\title{
APORTES DE LA CULTURA GRIEGA EN LA CONSTRUCCIÓN DE LA FILOSOFÍA DEL DERECHO CONTEMPORÁNEA ${ }^{1}$
}

\author{
Alejandro Robledo Rodríguez \\ Universidad Católica del Norte. Chile
}

\begin{abstract}
Resumen: El presente artículo busca evidenciar la visión que es posible desplegar desde la comprensión filosófica de la herencia griega en las instituciones jurídicas y en la formación de las ideas políticas. En tal sentido, pone de relieve la vigencia conceptual y estructural del legado cultural griego en contraste con los significados que en la filosofía del derecho tienen lugar.

Palabras Clave: Grecia - Filosofía - Dikè - Isonomía - Isoletía - Isegoría.
\end{abstract}

\section{CONTRIBUTIONS OF GREEK CULTURE ON THE CONSTRUCTION OF PHILOSOPHY CONTEMPORARY LAW}

Abstract: The present article seeks to demonstrate the vision that is possible to open from the philosophical comprehension of the Greek inheritance in the juridical institutions and in the formation of the political ideas. To this respect, it emphasizes the conceptual and structural force of the cultural Greek legacy in contrast with the meanings that in the philosophy of the right take place.

Keywords: Greece - History - Dikè - Isonomy - Isolety - Isegory.

Recibido: 16.01 .13 - Aceptado: 4.04 .13

Correspondencia: Alejandro Robledo RodríGuez. arobledorodriguez@gmail.com Licenciado en Ciencias Jurídicas, Universidad Católica del Norte, Coquimbo. Miembro de la Sociedad Chilena de Filosofía Jurídica y Social y de la Asociación Chilena de Filosofía.

(c) Doctor en Universidad de Los Andes, Santiago de Chile.

${ }^{1}$ Texto de ponencia presentado en el II Congreso Internacional de Estudios griegos, 12 de Octubre de 2011. Centro de Estudios Griegos, Universidad de Chile. Santiago de Chile. 


\title{
Introducción: El rol de la Filosofía del Derecho en la comprensión de la tradición filosófica griega ${ }^{2}$
}

\author{
"Nada me enseñan los árboles y las flores, sino los hombres en la ciudad". \\ [Platón, Fedro].
}

"No se puede ser filósofo del Derecho si no se es, lisa y llanamente, un filósofo" [G. Kalinowski, Estudios de Lógica Deóntica, Introducción]

in lugar a dudas, explicar la manera en que la Filosofía del Derecho puede interpretar los aportes del mundo griego a la cultura occidental y en particular, al sistema de la justicia es una cuestión compleja. No obstante, la propia vocación de la reflexión iusfilosófica es un llamado a desplegar tal empresa. En dicho orden, el vocativo expresado por Celso (ubi homo ubi societas, ergo ubi ius), resulta en este sentido del todo apropiado. Por la misma vía, Legaz y Lacambra ha sostenido muy atinadamente la idea de que en cualquier manifestación cultural en la que tomemos interés u observemos detenidamente, podremos constatar que el predicado tradicional que, desde la gracia clásica pasando roma republicana e imperial hasta llegar a la modernidad, se hace del fenómeno jurídico ${ }^{3}$, esto es, el carácter pantonómico ${ }^{4}$ de la justicia, es una de

\footnotetext{
${ }^{2}$ A lo largo de la exposición utilizo el recurso expositivo antes que la mecánica científica para la exposición de razones, pues fue así como surgió la idea del presente texto. He preferido así referir las reflexiones con miras a un mejor entendimiento con el público que asistió al Congreso y por consideración a los organizadores y demás expositores, de forma tal que el texto haga eco a las preguntas y reflexiones surgidas en dicha oportunidad. Nuestros agradecimientos a Jacqueline Ortiz por su diligencia y cordial trato, antesala de un diálogo fluido y consistente.

${ }^{3}$ Para una mayor claridad del porqué hablamos de fenómeno jurídico antes que de "Derecho", ver, Cuneo M. Andrés. Materiales para un estudio del fenómeno jurídico. (1996). Ed. Jurídica. Santiago de Chile. $2^{a}$ ed.

${ }^{4}$ El término pantonomía de la justicia, es ocupado por W. Goldschmidt para explicar el carácter universal de la Justicia en el sistema de repartos proyectados. Para una precisión y nuevas perspectivas el trabajo de Miguel Ciuro Caldani es abundante, ver entre otros: GoldschmidT, WERnER. Introducción filosófica al Derecho - La teoría trialista del mundo juridico y sus horizontes. (1957). Editorial Depalma; también, Ciuro Caldani, Miguel Angel. Metodología Dikelógica. (2007). Fundación para las Investigaciones Jurídicas. Rosario, Argentina.
} 
las notas que transversalmente comparte -como atributo configurador- con la propia cultura de la que es siempre tributario 5 .

La filosofía griega es pues, agente sedimentario en nuestra cultura y en la interpretación filosófica que hacemos de nuestras raíces. En este sentido, la filosofía, y particularmente, aquella parte especial que dedica sus esfuerzos al estudio de la justicia, esto es, la Filosofía del Derecho ${ }^{6}$, cumple, en primer lugar, una misión actualizadora, pues entre sus objetivos primarios está la de realizar una labor que podría llamarse, anamnética ${ }^{7}$, en el sentido de que, al ilustrar y comprender las distintas categorías y estatutos que sirven de base para el entendimiento o dilucidación sobre la pregunta esencial sobre ¿Qué es el Derecho? ${ }^{8}$ lo que se propone en realidad es extraer, por medio de la reflexión metódica, ciertos elementos que están presentes en el sentido común de quienes se aproximan a su estudio y análisis ${ }^{9}$. De hecho, en esta primera misión, puede detectarse un eco de la tradición cultural griega, canalizada -si se quiere- en sede platónica al partir de la base de ciertos elementos comunes que sirven de para estudio mediante una especie particular de reminicencia ${ }^{10}$. De ahí que tome estos "lugares comunes" que forman parte del acervo cultural (occidental) y los "actualize", dándoles un contenido más preciso y acotado, o sea, delimitando sus márgenes -sin que por ello de petifiquen- para generar un espacio más propicio para el diálogo filosófico en, como en egología $\mathrm{a}^{11}$ se suele decir, "interferencia

${ }^{5}$ Ver, Hart, Herbert. El concepto de derecho. (1992). Ed. Abeledo Perrot. Buenos Aires. Argentina.

${ }^{6}$ Sobre el particular pueden referirse algunos textos que el autor sigue en esta materia: MANsON Terrazas, Manuel. Filosofía del Derecho. (2006). Ed. Olejnick. Santiago de Chile; Radbruch, Gustav. Introducción a la Filosofía del Derecho. (2005). Ed. Fondo de Cultura Económica. 9a reimpresión. México.

7 "Si es verdadero lo que tu acostumbras a menudo, de que el aprender (mathesis) no es otra cosa que recordar (anamnesis) es necesario que hayamos aprendido, en un tiempo anterior, aquello de lo que ahora nos acordamos. Y eso no sería posible si nuestra alma no hubiera existido en otro lugar antes de llegar a ser en esta forma humana. De este modo también por ahí parece que el alma es algo inmortal”. PLATÓN. Diálogos. (1987). Siete volúmenes. Ed. Gredos. Madrid. España. Fedón. 72e.

${ }^{8} \mathrm{Si}$ bien es cierto, las respuestas a la pregunta ¿qué es el Derecho? Son del más extenso alcance, ello no obsta a que siga siendo ésta la pregunta inicial de mayor relieve y connotación para toda la reflexión filosófico-jurídica.

${ }^{9}$ V.gr. el mandato o imperio, la sanción, la razonabilidad, la alteridad, entre otras.

10 "Esse est remisci". El intuicionismo ha hecho de esta formula una metodología filosófica, con matices y límites diversos, pero en ideas, la pre-concepción de ideas es lo que aquí juega como argumento en la exposición.

${ }^{11}$ Esencialmente la egología supone comprender que: a) el derecho es conducta en interferencia intersubjetiva; b) el derecho considera todas las acciones humanas; c) el derecho se interesa por el acto humano en su unidad; d) el derecho supone la posibilidad de actos de fuerza; e) la libertad 
intersubjetiva". Por otro lado, cumple una misión reflexiva (filosófica), operando sobre las categorías planteadas al razonamiento y a la comprensión humana, de un modo contrastante con la realidad jurídica y social en que tales categorías, instituciones o bienes se construyen o dibujan. En este sentido, la labor de comprender es anterior a la de reflexionar, que a su vez es antecesora de la tarea de explicar (cosa de la que se ocupan, como diría Carlos Cossio, la fenomenología de la sentencia antes que la filosofía de la justicia o del derecho). Por último, la Filosofía del Derecho, cumple -según nuestra impresión- un rol generativo (constitutivo), precisamente por cuanto, al tomar las categorías ya actualizadas (por ejemplo, en nuestro caso, la isoletía o igualdad en los tributos) que son de suyo objeto de la comprensión jurídica, y reflexionando sobre sus alcances en la sociedad moderna, re-construye el mismo concepto y le otorga un contenido material y axiológico, que si bien, tiene siempre un peso histórico cultural, cobra una vigencia diversa en este proceso de actualización-generación, aunque consciente de sus orígenes, y que permite que la comprensión de dicho concepto, institución o bien, sea fácilmente adquirido o recepcionado por el lenguaje cultural en cada momento histórico ${ }^{12}$. Así la concepción de la Democracia no es la misma hoy que hace tres siglos, pero sin embargo, su significancia se mantiene comprensible para todas las personas ${ }^{13}$. De este modo, la triple labor (Anamnética, Filosófica y Constitutiva) es entonces una cuestión trascendental, cuya vocación primordial es la de construir un Estado de cosas (una polis, es sólo una manifestación de este estado) que sea en sí mismo enriquecedora del sistema de justicia, y que siendo fecundamente actualizada y reflexionada por quienes la hacen posible, contribuye sistemáticamente a la realización de una interacción social más plena y consiente.

Desde luego, lo antes mencionado tiene principal acogimiento en la formación de los nuevos juristas, en tanto en cuanto que, un estudio reflexivo filosófico, más bien) sobre las razones, por ejemplo que tienen lugar para la elección de un

es ineliminable contenido del derecho; f) las normas jurídicas conceptualizan la conducta en interferencia intersubjetiva y g) las normas jurídicas imputan sanciones y son juicios disyuntivos. La polémica de C. Cossio con H. Kelsen, es en este sentido muy notable.

${ }^{12}$ Para expresarlo con un ejemplo: lo justo como lo legal, no es sinónimo de lo justo natural. Ambos conceptos tienen pesos diversos en la historia de las ideas jurídicas y en la filosofía que expresan. No obstante, aun hoy podemos disputar el peso de su significado en la etapa de actualización. Una cosa es lo que dice la ley y otra su espíritu.

${ }^{13}$ Existe una variabilidad en la significancia con que expresamos por ejemplo los términos de una justa igualdad o de la igualdad a la ley, pero su significado, en términos globales, se nos representa con una carga de sentido que nos permite hablar de ella con vocación global. 
sistema u otro de justicia (talión o justicia conmutativa, o bien un tipo de justicia reparativa o preventiva, la razonabilidad de la diversidad de cultos; la existencia o no de pena de muerte, entre otros) o que hacen que en una sociedad haya o una democracia o un teocracia, devienen segñun el prisma una Filosofía del Derecho, entre otros factores, de la pantonomía cultural y dikelógica en que nos encontramos inmersos, en sus múltiples declinaciones (sociológicas, históricas, psicológicas, normológicas, entre otras), es algo que se origina en las raíces de su propia cultura o paradigma basal de construcción social ${ }^{14}$. Es en este sentido que decimos que la Filosofía del Derecho cumple una misión actualizadora. El rol de la educación y de la cultura, es clave para comprender cómo la conciencia sobre las raíces de las sociedades occidentales, pueden determinar que el ejercicio de los principios no sea meramente declarativo. La educación y la conciencia de la propia historia, así como la filosofía que es posible desarrollar en el seno de una sociedad de justicia, son elementos, esenciales para el perfeccionamiento de nuestro propio legado, y especialmente de los grandes aportes de la cultura griega: La propia Filosofía, la Democracia y la Justicia.

La intención precisa de estas reflexiones es entonces, la de un volver a los legados y aportaciones de la Grecia clásica, entendiendo que tal empresa, más que un desafío de actualidad o realización (realizativo, diría J. L. Austin ${ }^{15}$ ), se vuelve una labor complementaria y necesaria. Así lo indican grandes tratadistas como Legaz y Lacambra, Fassó, Gayo, Kunkel, o Mommsen, entre otros tantos, en el espectro iusfilosófico e histórico jurídico.

En nuestro opinión, el débito cultural y su actualidad son dos consideraciones que se tratarán poniendo énfasis en algunos conceptos claves (logos, topoi, mores, justicia, epikeia, democracia, igualdad, isegoria, isoletía, isonomia) y cómo aportan a la construcción más integral de una comprensión fenomenológica del derecho, más allá de los formalismos y arquetipos dados. Desde otra perspectiva, pretende llevar a un nivel más alto de abstracción las

${ }^{14}$ Claramente, el acervo cultural de una cultura como la iraní u otras que desarrollan un sistema de justicia teocrático, no es el mismo que el polaco o un sistema del sistema del Common Law. Esta apreciación tan común o evidente, tiene de una manera no tan clara, raíces mas intrincadas en una explicación y comprensión de sus visiones propias, mas allá de un simple paralelo sistémico.

${ }^{15}$ Cfr. Austin, John. L.: Cómo hacer cosas con palabras, Paidós, Buenos Aires, 1971. Algún autor le ha confundido más de una vez, muy desafortunadamente con Austin, John. The Province of Jurisprudence Determined. Indianapolis: Hackett. Este último fue discípulo e Jeremy Bentham y cuyos estudios se centraron en el lenguaje directivo y la jurisprudencia. En la claridad de esta nota estoy en deuda con Manuel Manson. 
lecturas que tradicionalmente se efectúan sobre la filosofía griega de algunos grandes filósofos, como la de Sócrates, Platón o Aristóteles, al tiempo que evidencia como su obra trasciende y resulta actual para la construcción del Derecho contemporáneo. En este sentido, divide su atención en tres grandes enunciados, el primero, relativo a dilucidar con profundidad los aportes de la filosofía griega clásica al mundo jurídico, enlazando un estudio histórico y filosófico de algunos conceptos esenciales (1); el segundo, cuya atención se centrará en la actualidad de dichos aportes y la manera en que estos coadyudan a la idea de un sistema integral de justicia aplicable a sociedades occidentales (2); y finalmente, analiza en una perspectiva expansiva, la idea del débito cultural, que es la base y origen de muchas de nuestras actuales ideas, instituciones y categorías sociales, políticas y jurídicas.

\section{1.- Los aportes de la Filosofía griega a la Historia de la Cultura Jurídica}

De ordinario, el lector lego puede encontrarse con reflexiones que, en torno a la idea de Derecho, la idea de lo justo, o lo equitativo, se recurra primariamente a fuentes latinas. Ello es común en la mayoría de los textos que se utilizan para introducir a los estudiantes al mundo jurídico. También ocurre así en casi todas las reflexiones dogmáticas que se efectúan sobre instituciones o sistemas. Con todo, el intento siempre constante de la Filosofía y como hemos dicho de la Filosofía del Derecho, apunta una reflexión más honesta y no segmentaria o lineal, si se quiere. Pues bien, sabemos que es casi un hábito -en Derecho estricto- y lugar común en la enseńanza del mismo, señalar que nada tendríamos los hombres de hoy, si los romanos no hubiesen inventado el Derecho en tanto institución. Con todo, esta reflexión inicia de un punto de partida erróneo, ya históricamente ${ }^{16}$, ya filosófica, ya metodológicamente ${ }^{17}$. El error es histórico, como señalan Kunkel ${ }^{18}$, Daimon y Mommsen, toda vez que el hecho que dio lugar al primer texto positivo del que hay registro en Roma, a saber las XII

${ }^{16}$ En este sentido seguimos la opinión de CARTLEdge, PAul. Los griegos: Encrucijada de la civilización. (2001). Traducción castellana de Mercedes García Garmilla. Barcelona. España. Crítica.

${ }_{17}$ Así por ejemplo:"Entre muchas instituciones del derecho marítimo griego, es conocido el préstamo mercantil o préstamo a la gruesa, que osteriormente habrían de copiar los romanos dándole el nombre de "fenus nauticum»". DEMÓSTENES. Discursos. Edit. Gredos. Madrid, 1983. Citado por Alonso y Royano, Felix. El Derecho Griego. (1996). Revista Espacio Tiempo y Forma. Serie II. Historia Antigua. T.9. p.119.

${ }^{18}$ Kunkel, Wolgang. Historia del Derecho Romano. (1989). Barcelona. España. trad. J. Miquel, 9a ed. p. 26. En el texto se expresa "Así la escritura de los romanos, el alfabeto latino, se hace derivar del etrusco, el cual, a su vez, procedía del griego”. p.12 
Tablas, tuvo su origen en una revuelta acaecida en la Roma arcaica alrededor del año 716 a.c. producto de la cual se enviaron emisarios (deccenviros) a las polis griegas con el objeto de estudiar su constitución y en especial las leyes de Solón, para que con este ejemplo a la vista, se pudiere dar curso a una Roma que solo 200 años mas tarde vería sus primeras luces con el advenimiento de la República. Por otro lado, el error es filosófico, pues la mayoría de los grandes políticos romanos y que dieron cuerpo a la institucionalidad republicana e imperial, y en gran parte al legado jurídico romano, tuvieron una honda y profunda vinculación con el mundo griego, especialmente con su filosofía. Ejemplos notorios son Marco Aurelio (121-180), Cicerón (106-43 a.C) y Heródoto $(484-420 \text { a. C })^{19}$. Finalmente, no valorar o restar significancia al acervo cultural griego en el orbe de las reflexiones jurídicas constituye un error metodológico, pues nada tendríamos de Roma si antes los romanos no hubiesen heredado, y en muchos casos replicado, elementos trascendentales de la filosofía, el derecho ${ }^{20}$ y la cultura griega.

Lo antes enunciado, es útil para detenernos desde ya, en ciertos elementos sustantivos, que es dable apreciar e identificar toda vez que pensamos -filosóficamente- "lo jurídico", sin pretender universalidad o detrimento. En tal orden es menester apuntar algunas notas que perfilan de mejor manera la comprensión de los aportes, si dable decir, particulares del orbe griego. Sobre este punto coincidimos plenamente con Fassò quien apunta juiciosamente que "la reflexión filosófica, esto es, la meditación racional acerca de los magnos problemas humanos, como son la esencia del hombre, su destino, los principios rectores de su conducta y el significado y fin de la vida, tuvo su origen en Grecia. Pero no solamente eso, sino que nuestra forma de concebir la realidad, la cual ha influido profundamente, asimismo, sobre todo el otro gran componente de nuestro acervo espiritual: el cristianismo" ${ }^{21}$.

Un primer aporte en este sentido, está constituido por la búsqueda del Arjé, el principio o esencia del mundo, coincidente con la idea de lo verdadero (aletheia), lo real, permanente e inmutable, cuya profundidad conceptual va mucho más allá de la mudable apariencia. Es precisamente, sobre este primer centro impulsor

${ }^{19}$ HERODOTO. Historia. (1988). Introducción y notas de Carlos Schrader. Ed. Gredos. Madrid, España. ${ }^{20}$ Sobre los elementos del Derecho griego seguimos a Alonso Y Royano, Felix. El Derecho Griego. (1996). pp. 116 - 142. También la línea ver, WOLFF, H.J. La Historia del Derecho Griego. Disponible en: http://www.restudioshistoricos.equipu.cl/index.php/rehj/article/viewFile/7/7

${ }^{21}$ Fassò, Guido. Historia de la Filosofía del Derecho. Título original: Storia di la filosofía dil Diritto. (1982). V. I. Traducción e Juan Lorca Navarrete. 3ª Ed. Pirámide. Madrid. España p.17. 
que se desarrolla toda filosofía y que contrasta con nociones desarrollados en y por el mundo griego en profundidad: la doxa y la espiteme. La primera, identitaria de la mera opinión y con el rasgo característico de mutabilidad o apariencia, la otra constituida por un conocimiento que está mas intrínsecamente vinculado a la realidad misma, al verdadero trabajo de la Filosofía como búsqueda de sabiduría. Extrapolados estos términos, al ámbito de reflexión iusfilosófica, podría decirse que la pregunta esencial sobre ¿Qué es el Derecho? O bien ¿Qué es la Justicia?, es una pregunta que apunta a vislumbrar el Arjé del fenómeno jurídico, respuesta que en la Historia de la Cultura, ha revestido y reviste aún hoy, tanto el carácter de una mera opinión (doxa), bien el modo de una investigación que intenta aproximarse al objeto de estudio más allá de lo formal. Pero más allá de este primer nominalismo, lo que sustancialmente (substratum, esto es, "estar debajo de", es una categoría que empleara Aristóteles antes que cualquier jurista romano) subyace es una comprensión filosófica en orden a la razones que pueden darse en torno a la pregunta esencial en sede iusfilosófica.

En otras palabras, así como veremos luego, existen platonismos, o aristotelismos en toda la gama de explicaciones doctrinarias sobre el Derecho, así también encontramos explicaciones que son bien meras opiniones (doxa), o bien explicaciones epistemológicas.

Ahora bien, desde un punto de vista filosófico y político, podemos centrar nuestro análisis en los filósofos presocráticos, quienes de ordinario son representados como guidados casi exclusivamente por un enfoque naturalistico (physis), aunque en realidad sus ocupaciones en la vida social y política de Grecia, no son desde luego, superficiales ni únicamente naturalísticas. Tan es así, que Tales de Mileto, además de su preocupación por la naturaleza, ya antes de había ocupado de la política ${ }^{22}$; lo propio hizo Parménides sobre las leyes, Zenón de Eléa con respecto al régimen tiránico o Empédocles con respecto a la Democracia en Agrigento. Por su parte en la Escuela Jónica, Anaximandro, nos dirá que "de aquello de donde provienen necesariamente los seres procede también su disolución, porque así se abonan recíprocamente la reparación (dikè) y la satisfacción de la injusticia (adikía)" ${ }^{23}$. Por su parte Parménides apuntará que "las llaves de los senderos de la noche y del día los guarda Dikè" 24 , y es ella quien

${ }^{22}$ Cfr. Guthrie, W. K. C. Los filósofos griegos de Tales a Aristóteles. (1994). Traducción de Florentino M. Torner. Fondo de Cultura Económica Chile. Santiago, Chile.

${ }^{23}$ Diels - Kranz. Die fragmente der Versokratiker. B 1, 13-14. p. 28. Citado por FASSO, Guido. (1982). p. 24.

${ }^{24}$ Jaeger, Werner. Paideia: los ideales de la cultura griega. (1992). Traducción de Joaquín Xirau y Wenceslao Roces. Fondo de Cultura Económica. México, D.F. p. 22. 
domina el Ser. En palabras de Fassò, y como ejemplo del significativo aporte de la filosofía presocrática, la filosofía de Parménides resulta indicativa, pues fue él quien primero aplica "al universo físico, el concepto ético-jurídico del deber ser, personificado en Dikè, la Justicia”25.

Esta idea del Derecho como Dikè, encuentra su expresión en la obra de Hesíodo, "Las obras y los días", en que predomina la idea de que la arbitrariedad de quienes quieren imponer su voluntad (hybris) debe ser objeto de un castigo por la justicia (Dikè). En efecto el fragmento del poema de Hesíodo que se inicia con la fábula del gavilán que ha capturado a un ruiseńor, le previene al lector de no oponerse a quien es más fuerte que él, aunque el poeta por el contrario, como anota Fassò, "exhorta a la necesidad de no atender más que a la pre-potencia a la justicia, que es la que finalmente triunfa siempre". Posteriormente, Homero en la Ilíada ${ }^{26}$, señalará "brota el convencimiento de que la ira de Zeus se desencadena cuando los hombres decretan leyes injustas o no observan la justicia”. Por otro lado, recordemos que en la Odisea, Telémaco manda interrogar a Néstor por ser el mejor conocedor de la justicia" ${ }^{27}$ vemos elementos de la filosofía griega que resultan perceptibles aun hoy en día. Esta deuda histórico-cultural tiene en Parménides, Heráclito, Sócrates, Homero ${ }^{28}$, Platón, Aristóteles y Hesíodo sus representantes más altivos. Rubrica lo expuesto, la idea sostenida por Jaeger para quien el argumento Homérico expuesto en la propia Odisea está presente la idea de que la justicia es un signo de civilización y es considerada como elemento de la organización jurídica de la sociedad, ya que los "salvajes cíclopes no tienen leyes $^{29}$. Existen igualmente otros ejemplo que hacen referencia al contenido normativo y a la noción de imperio aplicada al orbe griego, así en la Antígona de Sófocles, podemos ver el concepto que tuvieron los griegos de las leyes, como

${ }^{25}$ FAssó, Guido. (1982). p.22.

${ }^{26}$ HOMERO, Iliada, XVI, p. 487.

${ }^{27}$ FAssó, Guido. (1982). p. 20.

${ }^{28}$ Como bien señala Jaeger "No es posible actualmente considerar la Ilíada y la Odisea - fuentes de la historia primitiva de Grecia- como una unidad, es decir, como obra de un solo poeta, aunque en la práctica sigamos hablando de Homero, tal como lo hicieron originariamente los antiguos, incluyendo bajo este nombre múltiples poemas épicos. El hecho de que la Grecia clásica, exenta de sentido histórico, separara ambos poemas de aquella masa, considerándolos como superiores desde un punto de vista exclusivamente artístico y declarara a los demás indignos de Homero, no afecta a nuestro juicio científico ni puede considerarse como una tradición en el sentido propio de la palabra. Desde el punto de vista histórico, la Ilíada es un poema mucho más antiguo. La Odisea refleja un estudio muy posterior de la historia de la cultura”. En JAEGER, Werner. (1992) p. 30.

${ }^{29}$ HOMERO. Odisea. III. p.244. 
themis ${ }^{30}$, esto es, el decreto sagrado revelado a los reyes por los dioses por medio de los oráculos o de forma onírica, cuya particularidad consiste en la posibilidad que tienen de transmitirse de padres a hijos, en tanto que norma dominante del grupo gentilicio y que incluso constituye el patrimonio de la clase dominante ${ }^{31}$, es una nota esencial. Pues bien, de una sociedad en que hay predominancia de los themis (donde las primarias reflexiones de la filosofía son también conductoras de la polis y del mundo) se pasará luego, a una sociedad imperada por la idea de dikè o justicia, en la que existe un predominio de la idea racional (logos) de igualdad (isonomía), de modo tan profundo que si la Themis responde a un tipo de sociedad aristocrática, la justicia (Dikè) la prudencia (sophrosyne) son el inicio de la sociedad democrática griega ${ }^{32}$.

Otro concepto de interés y conjuntivo con los antes mencionados, es el de Areté $^{33}$. Los griegos, como señala Jaeger, por este concepto comprendían, sobre todo, una fuerza, una capacidad. A veces la definen directamente, aunque ello no es frecuente. Las mas de las veces, la designan como "el vigor y la salud" que son arete del cuerpo" 34 . Por el contrario, aunque con la misma idea se designa la "sagacidad y penetración", esto es, un arete del espíritu. Como es claro, es difícil compaginar estos hechos con la explicacón subjetiva, ahora usual, que hace derivar la palabra de "complacer" $(\alpha \rho \varepsilon ́ \sigma \kappa \omega)^{35}$. En este sentido, Jaeger clarifica de modo preciso que "es verdad que areté lleva a menudo el sentido de reconocimiento social, y viene a significar entonces "respeto", "prestigio". Pero

${ }^{30}$ Del plural Themistes.

${ }^{31}$ Si bien este carácter extrahumano de la legalidad no durará siempre, tendrá ecos incluso hoy en día en las doctrinas que intentan dar comprensión a las teorías de la justicia aplicables a sociedades democráticas modernas.

32 "Si las dos palabras suelen traducirse conjuntamente en nuestra lengua como "justicia", es lo cierto que la concepción de justicia, que cada una de ellas expresa, es totalmente diferente: manifestación de la voluntad superior del hombre la primera, producto de la razón y de la experiencia humana la segunda" FASSÒ, Guido. (1982). p. 19.

${ }^{33}$ Lledó apunta al efecto que "el término griego areté no encuentra una traducción muy exacta en la palabra virtud, ya que esta traducción tiene demasiadas resonancias «morales» - "hombre virtuoso", "acciones virtuosas», que, en principio, no están en la experiencia griega. Pero sí hay algo común en ambas palabras: su significado de excelencia, de mérito, de bueno, de positivo para quien lo posee. Esas cualidades se consideraron innatas en los comienzos de la cultura griega”. Lledo, Emilio; Granada, Miguel; Villacańas, José Luis; Cruz. Manual Historia de la Filosofía. (1997) Ed. Santillana. Madrid, España, p. 52.

${ }^{34}$ De hecho en la literatura griega clásica es dable encontrar varias especies de areté. Así Areté del caballo $\Psi$ 276, 374, En PLATÓN. La República. (1988). Introducción de Manuel Fernández Galiano; [traductor José Manuel Pabón y Manuel Fernández-Galiano]. Madrid. Alianza Editorial. reimp. 1997.552 p. 335 B, donde se habla de la areté de los perros y los caballos. En $353 \mathrm{~B}$, se habla de la areté del ojo. Areté de los dioses, I 438.

${ }^{35}$ Ver, M. Hoffmann. Die ethische Terminologie bei Homer, Hesiod und den alten Elegikern und lambographen. (1914). Tubinga. p. 92. Citado por FASSO, Guido. (1982). p. 17. 
esto es secundario y se debe al fuerte contacto social de todas las valoraciones del hombre en los primeros tiempos. Originariamente la palabra ha designado un valor objetivo del calificado en ella. Significa una fuerza que le es propia, que constituye su perfección" 36 , es lo que el mismo autor aprecia valora señalando: "El pueblo griego trasmitió, sin duda, a la posteridad una riqueza de conocimientos imperecederos en forma imperecedera" 37 .

Ahora bien, conviene preguntarnos, si es posible extraer aprendizaje o mejor dicho si es posible aprender algo de estos aportes que la Filosofía griega ha efectuado a nuestro acervo cultural y a nuestras ideas sobre la justicia. La pregunta, en su sentido filosófico, puede llevarnos a otra más intensa: “¿Podemos como seres humanos mejorar nuestra naturaleza?"38. La respuesta hecha desde una lectura de del Menón nos indicará que es posible aprender determinadas formas de excelencia humanas, cuya finalidad es el conocimiento de sí mismo ${ }^{39}$. La areté, argumenta Lledó, "radica pues, en el conocimiento, porque, al preguntar si podemos aprender una forma de hacer mejor nuestra condición natural, tenemos que saber, en primer lugar lo que buscamos y lo que queremos ser ${ }^{40}$.

Finalmente creemos que, rasgos comunes a cualquier explicación o respuesta al pregunta esencial sobre la naturaleza el Derecho o la justicia, pueden interpretarse como vigencias trascendentales de la filosofía griega, así nos atrevemos a señalar que no hay Derecho si primero no se reconoce la Isonomía, esto es, la igualdad ante la ley; la Isegoría, esto es, la igualdad de voz en el foro y en un ámbito más restringido pero igualmente relevante, la Isoletía, o la igualdad en los tributos o cargas públicas. Aunque claramente el aporte más fundamental está dado por el concepto de Democracia ${ }^{41}$, como el gobierno de los iguales.

\section{2.- Actualidad de los conceptos filosóficos del acervo cultural griego en la comprensión iusfilosófica contemporánea}

Antes que hacer una disección terminológica que implique una suerte de selección de aportes, pensamos que lo propio en materia filosófica es precisamente no catastrar

${ }^{36}$ FAssó, Guido. (1982). p. 23.

${ }^{37}$ JAEGER, WERNER. (1992). p. 13.

38 Lledo, Emilio; Granada, Miguel; Villacañas, José Luis; Cruz. Manual. Historia de la Filosofía. (1997) Ed. Santillana. Madrid, España. p. 52.

${ }^{39} \mathrm{El}$ "primus inter esse" a distancia del "primus inter pares", para decirlo en tono romano.

${ }^{40}$ Lledo, Emilio; Granada, Miguel; Villacañas, José Luis; Cruz.. (1997). p. 52.

${ }^{41}$ "Que nace, creo yo, al vencer los pobres» y extender el poder, por elecciones, a todos. La ciudad se llenará, así, de libertad y es posible escoger otras formas de vida: Será también el más bello de los sistemas. Del mismo modos que un abigarrado manto en que se combinan todos los colores, así también este régimen, en el que hay tantas posibilidades, puede parecer el más hermoso". PLATÓN. República. 557c. 
-cosa que incumbe a otras ciencias u oficios- sino reflexionar la consistencia de los aportes que son objeto de nuestro estudio, de modo que, arrancando de ciertos elementos básicos podamos vislumbrar la actualidad del acervo griego.

Pues bien, si miramos las cosas con cuidado y sin prejuicios, podremos ver que en las muy variadas reflexiones sobre la naturaleza del Derecho o lo que es lo mismo, dentro de las múltiples preguntas que se hacen acerca de lo que ya hemos dicho antes ¿Qué es el Derecho? existen diversas respuestas que son dadas desde la óptica iusfilósfica. En unos casos, se centran en el apego a la sola legalidad, como en el caso del positivismo jurídico analítico, y en otras en la ley natural que debe anteceder a toda ley escrita. En ello, desde el estudio de lo griego, puede verse un eco significativo y plenamente actual. Piénsese, por ejemplo en el dualismo de elección que se presenta en Antígona ${ }^{42}$, obra en que presenta el argumento de una elección no libre entre dos opuestos: las leyes de los hombres (diremos, leyes positivas) y las leyes de los dioses (diremos, leyes naturales) unas deben preferirse con antelación a las otras según puede verse en el texto ya clásico. Otra lectura que puede hacerse, deviene de este mismo contrapunto ley positiva-ley natural, y tiene un asiento en reflexiones que son la herencia más clara de la impronta griega en la actualidad. Así en Platón, sobre todo en La República, hay una clara vinculación reflexiva sobre la justicia, como un ideal extra polis, como un bien que se encuentra "fuera de la caverna" y de la cárcel del alma, que está finalmente más próxima a la idea suprema de bien en el toposuranus que en la realidad proporcional como la entendida por Aristóteles ${ }^{43}$.

Tan clara es la idea del legado y aporte griego a la construcción de nuestra ideas filosóficas y políticas, que podemos leer en Platón, por ejemplo, que "el Estado expresa en grande lo que el individuo en pequeño" ${ }^{44}$, de ahí que su visión del hombre y del alma humana sean proyectables a la polis, pudiendo distinguirse claramente de acuerdo a ello, tres niveles: Uno superior, correspondiente al logos, a la racionalidad

${ }^{42}$ Para una lectura más sistemática Ver: Solari, Enzo. Antígona o el poder de lo real. (1998). En: Persona y derecho: Revista de fundamentación de las Instituciones Jurídicas y de Derechos Humanos. No. 39, (Ejemplar dedicado a: Estudio sobre "Antígona"), págs. 173- 194 Disponible En: http://www.mercaba.org/FICHAS/Teologia_latina antigona_o_el_poder_de lo_real.htm

${ }^{43}$ Suele apreciarse en la literatura una confrontación entre el pragmatismo de herencia aristotélica y el idealismo de herencia platónica. La verdad es que ambas corrientes, tienen más en común de lo que se aprecia y sus orígenes están más vinculados a otras razones que a una lectura lineal de la filosofía de Platón o de Aristóteles. Así, por ejemplo, se puede explicar el complejo original del pragmatismo de James, más encaminado a la psicología que a la explicación del mundo natural.

${ }^{44}$ Podemos constatar el hecho y al mismo tiempo no estar de acuerdo con Platón, quien se representa como partidario de la razón de Estado, antes que del libre ejercicio de la razón humana. 
y a la reflexión, al cual pertenecerían los gobernantes (archontes) que han sido elegidos por los guardianes (phylakes) y que fundan su superioridad en el saber (sophia). Saber que es identificado con el altruismo, la generosidad y el idealismo. La misión de los gobernantes "filósofos» es legislar teniendo siempre presente la más rigurosa justicia, que es la virtud que hace posibles todas las otras. El segundo nivel, es el que incumbe a los guardianes, que concurren en defensa del Estado ante ataques exteriores. Sobre el particular, es interesante y notorio que Platón irrogue a las mujeres de esta clase los mismos derechos que los hombres. La isonomía entonces se vuelve filosófica y políticamente un elemento esencial ${ }^{45}$. La diferencia estará en los niveles de saber y no en las particularidades humanas o en el género. En consecuencia, Platón con su visión del hombre y la polis, expone, como apunta muy atinadamente Lledó que, "la parte del alma que corresponde a los guardianes es el thymos, el ánimo, la energía, la fuerza” 46 como características del alma individual, "intermedia entre lo racional (logistikón) y los movimientos instintivos del alma (ephitymetikón). Su virtud es el valor (andreía)" ${ }^{\prime 7}$.

Por último, el sustrato basal está identificado en Platón, por el pueblo, los campesinos y comerciantes y artesanos. Que lejos de no tener vocaciones, sustentan a las otras dos, pues son su fundamento económico y material. En este sentido es del todo efectiva la apreciación que señala que la función del alma que le caracteriza al pueblo, es la ephitymetikón que equilibra sus impulsos por la vida y el cuerpo.

Ahora bien, recordemos que fue el estagirita quien hizo uno de los primeros estudios de la justicia de manera sistemática como puede ver en el Libro VIII de la Justicia en la Ética Nocomaqued ${ }^{48}$, en que la define como una "cualidad moral que es causa de que se deseen o quieran hacer cosas justas" 49 y en que mas adelante, prepara una de las cuestiones de mayor relevancia para la construcción y comprensión de la idea de Derecho, cual es la preocupación por la especies de justicia (conmutativa y distributiva). Esta última cuestión, ya había sido desarrollada por juristas griegos y especialmente desde las leyes de Solón que tuvieron acogida en la reforma agraria impulsada por él. Así la justicia

\footnotetext{
45 "Por tanto, si empleamos a las mujeres en las mismas tareas que a los hombres, será menester darles también las mismas enseñanzas". PLATÓNRepública. 451e.

${ }^{46}$ Lledo, Emilio; Granada, Miguel; Villacañas, José Luis; Cruz.. (1997). p. 53.

${ }^{47}$ Lledo, Emilio; Granada, Miguel; Villacañas, José Luis; Cruz. (1997). p. 53.

${ }^{48}$ Texto utilizado, ARISTÓTELES. Ética a Nicómaco. (2008). Introducción, traducción y notas de José Luis Calvo Martínez. Alianza. Madrid. España.

${ }^{49}$ ARISTÓTELES. Ética a Nicómaco. (2008).
} 
conmutativa es la que compete al sinalagma ${ }^{50}$, o a la igualdad de prestaciones, y lo que incumbe a la justicia distributiva es la noción de reparto en función de los méritos u honores de que son detentadores los hombres en la ciudad.

En efecto, de esta delimitación conceptual hecha por Aristóteles ${ }^{51}$, gran parte de las reflexiones modernas sobre la justicia se han hecho eco casi obligatorio. Lo mismo podría decirse de su doctrina Hilemórfica en la enseñanza del Derecho o de la Epikeia. En cuanto a lo primero, muy actualmente, a propósito de las modernas teorías dela justicia, John Rawls dedica un extenso artículo titulado precisamente: "Justicia Distributiva” de justicia, esto es, igual libertad y justa igualdad de oportunidades para todos, imponen al acto de justicia distributiva en una sociedad democrática. Lo propio hace Robert Nozick en su texto "Justicia y orden socioeconómico: Teoría del título posesorio" 53 en que se plantea el eje de su esquema libertario de sociedad. Autores estos últimos, cuyos intereses se han centrado en descifrar como es posible establecer los límites de una las teorías de la justicia en las sociedades actuales. Su esfuerzo y tenor intelectual son, aunque no lineal ni históricamente, acuso de recibo de un esfuerzo iniciado hace mas de dos mil años en Grecia.

Pues bien, a propósito de las reflexiones político-filosóficas que antes exponíamos sobre Aristóteles, y de forma muy atinada, Lledó apunta que la "famosa definición del hombre como «animal que tiene lógos», un «animal

${ }^{50}$ La RAE define sinalagmático como: "Del gr. $\sigma v v \alpha \lambda \lambda \alpha \gamma \mu \alpha \tau t \kappa o ́ \varsigma$, perteneciente al contrato". Con esta definición nominal o tautológica no se permite comprender del todo su extensión y complejidad, pero ilustra la idea de prestación recíproca presente en todo contrato, en toda relación jurídica.

${ }^{51}$ Lamentablemente por una razón espacial no es posible referirnos acá al aporte de la filosofía aristotélica y griega al desarrollo ulterior de la lógica pero puede verse un muy extenso y profundo trabajo al respecto En: LuKasiewicz, Jan. La silogística de Aristóteles desde el punto de vista de la lógica formal moderna. (1977). [traducción. de la 2a. ed. por Josefina Fernández Robles]. Ed. Tecnos. Madrid. España. 181 p.

${ }^{52}$ Traducido con la debida autorización del libro Economic Justice, Penguin Books, Inc., 1973, Capítulo $4^{\circ}$, Sección 13, pp. 319-362. Este ensayo, tal como figura aquí, comprende el texto completo de "Distributive Justice" (1967) y la parte principal de "Distributive Justice: Some Addenda". Disponible En: Revista del Centro de Estudios Públicos (1986). Santiago de Chile. № 21.

${ }^{53}$ Traducido del libro Anarchy, State, and Utopía, Capítulo $7^{\circ}$. Sección 1, Nueva York: Basic Books, 1974, pp. 150-182. En el original el ensayo se titula "The Entitlement Theory". Traducido y publicado con la debida autorización. La obra completa aparecerá próximamente en castellano por el Fondo de Cultura Económica, México. Esta traducción realizada por el CEP ha tratado de respetar los términos utilizados por el autor, reconociendo que en algunos casos no son los más adecuados en español. Disponible En: Revista del Centro de Estudios Públicos, Santiago de Chile No 26, 1987, http://www.cepchile.cl/dms/lang_1/doc_791.html 
que habla» (...), expone la natural sociabilidad del ser humano. La ciudad es, por tanto, un lugar donde el hombre realiza, necesariamente, su vida; donde habla y se comunica" 54 . En efecto, es conocida y actual la significancia que en la formación de la lógica del discurso esta definición ha tenido. Sus consecuencias en torno a la pregunta vital ¿Qué es el hombre? Son y han sido abordadas desde las más variadas perspectivas, entre otras, puede recordarse la definición de la que arranca Boecio tomando la referencia de Porfirio -estudioso de Aristóteles- sobre el hombre como "sustancia individual de naturaleza racional" 55 .

Ahora bien, por lo que respecta al eco del hilemorfismo, aunque solo por analogía ${ }^{56}$, podríamos decir que es cosa habitual distinguir, en el pensamiento jurídico, entre elementos que con esenciales o materiales (bile) en un acto jurídico o un contrato sinalagmático, como son la voluntad (bybris) la causa y el objeto y elementos formales (morfos) como son la licitud y la publicidad. Finalmente un eco no frecuentemente tenido a la vista por los estudiosos del derecho, y especialmente por el Derecho civil, es el desarrollo que el Filósofo hace de la teoría de la causa y sus clases. Lo que decimos entonces, es que este entendimiento puede deberse -claro está- al trabajo intenso de los juristas romanos y sus sucesores, pero ya antes lo había clarificado un filósofo griego heredero ${ }^{57}$ de la más intensa filosofía: la griega.

\section{3.- El débito cultural y sus implicancias}

\section{La filosofía griega y el fundamento de la educación}

La educación en filosofía es pues uno de los aspectos esenciales de la idea de un débito cultural hacia Grecia. Su herencia e impronta, con mayor o peor fortuna, están siempre presentes en la construcción filosófica de la cultura y en la educación.

Nuestra deuda, lejos de ser meramente declarativa, encuentra en la experiencia política y filosófica griega, un eco profundo cuyo estudio nos da luces incluso de los problemas actuales de la educación en la actualidad. Baste recordar lo

\footnotetext{
${ }^{54}$ Lledo, Emilio; Granada, Miguel; Villacañas, José Luis; Cruz.. (1997). p. 39. Existe un texto completo en inglés: ARISTOTLE. Sofistical Refutations, (1985) 5, 167a37. The Complete Works of Aristotle. The revised Oxford Translation. Edited by Jonathan Barnes. Vol. I. p. 283. Princeton University Press. Princton, New York.

${ }^{55}$ Ferrater Mora, Fernando. Diccionario de Filosofía.

${ }^{56}$ Esto es algo que también debemos a Grecia, y el Derecho es especialmente tributario en este sentido.

${ }^{57}$ Ver, DEMÓSTENES. Discursos. Edit. Gredos. Madrid, 1983.
} 
expresado por Aristóteles para graficar lo expresado, cuando al referirse al método de Gorgias señala: "La educación de los que cobraban por los discursos erísticos era semejante al método de Gorgias. Pues unos daban para aprender de memoria piezas oratorias, otros daban cuestionarios, temas ambos en los que unos y otros creían que recaían las argumentaciones recíprocas. Por esa razón la enseñanza era rápida pero falta de fundamento. Ya que creían educar ofreciendo no la técnica y el método, sino los resultados de esa técnica, de modo semejante a como si uno prometiera transmitir conocimientos sobre cómo evitar el dolor de pies y no enseñara ni la técnica de hacer zapatos, ni dónde obtener tales conocimientos, sino que se limitara a presentar distintos tipos de calzado" ${ }^{58}$.

\section{La Filosofía griega y el derecho}

Volviendo a nuestro argumento inicial (ubi homo ubi societas, ergo ubi ius), referido por Celso, puede resultar más comprensible la conexión entre la cultura griega y su relación con lo jurídico. Pues bien, donde quiera que exista el hombre y se pregunte sobre los límites de su existencia y las razones de la misma, donde quiera que exista la sociedad, nos dice el jurista romano, existirá el Derecho, pero antes que la pregunta sobre ¿Qué es lo justo? Primero es la pregunta sobre ¿Qué es el hombre? La relación implícita entonces y ahora mismo, radica en la consustancialidad del pensamiento filosófico y la reflexión sistemática por la justicia. Sus objetos son diversos pero el núcleo de sus atenciones el mismo: El prosopon griego y la persona humana actual, en su complejo de relaciones vitales.

\section{A modo de Conclusión}

Como corolario reflexivo, debemos decir que fuerza la razón del filósofo que se dedica al estudio de la justicia, ver mucho más allá del propio tiempo y de las propias instituciones. Claro esta que en las raíces de la Historia de occidente cada núcleo o paradigma ha transcendido intensamente en sus particularidades, ( la idea de justicia distributiva, de trascendencia, de virtud o democracia son algunos ejemplos que rubrican lo dicho) mas el primer asiento reflexivo y que posibilitó el surgimiento de occidente como tal y en consecuencia, muchas de nuestras actuales virtudes e instituciones, han venido del mundo de la reflexión filosófica griega, a esta herencia debemos -siempre- la reflexión seria y sostenida, un estudio comprensivo y no sombrío, sino significativo de un legado trascendental.

\footnotetext{
${ }^{58}$ ARISTOTELES. Refutaciones sofisticas. 183c36- 184a75. Citado por FASSÒ, Guido. (1982). Historia de la Filosofía del Derecho. Título original: Storia di la filosofía dil Diritto. V.I. Traducción de Juan Lorca Navarrete. $3^{a}$ Ed. Pirámide. Madrid, España. p. 76.
} 


\section{Referencias bibliográficas}

Alonso y Royano, Felix. El Derecho Griego. (1996). pp. 116 - 142. WOLFF, H.J. La Historia del Derecho Griego. Disponible en: http://www. restudioshistoricos.equipu.cl/index.php/rehj/article/viewFile/7/7

Aristóteles. Etica a Nicómaco. (2008). Introducción, traducción y notas de José Luis Calvo Martínez. Ed. Alianza. Madrid. España. 315 p.

Aristóteles. Refutaciones sofísticas. (1982). 5, 167a37a (orgánon), I, Categorías, Tópicos, Sobre las Refutaciones Sofísticas. Introducción traducción y notas de Miguel Cardel San Martín. Ed. Gredos. Madrid, España.

Cartledge, Paul. Los griegos: Encrucijada de la civilización. (2001). Traducción castellana de Mercedes García Garmilla. Ed. Crítica. Barcelona. España. 222 p.

Crombie, I. M. Análisis de las doctrinas de Platón. (1990).Versión española de Ana Torán y Julio César Armero. Madrid. Alianza. 2 v.

Cuneo M. Andrés. Materiales para un estudio del fenómeno jurídico. (1996). Ed. Jurídica. Santiago de Chile. $2^{a}$ ed.

Demóstenes. Discursos. Edit. Gredos. Madrid, 1983.

Fassò, Guido. Historia de la Filosofía del Derecho. Título original: Storia di la filosofía dil Diritto. V. I. Traducción de Juan Lorca Navarrete. $3^{a}$ Ed. Pirámide. Madrid. España.

Ferrater Mora, Fernando. Diccionario de Filosofía.

Guthrie, W. K. C. Los filósofos griegos de Tales a Aristóteles. (1994). Traducción de Florentino M. Torner. Santiago. Fondo de Cultura Económica Chile. Santiago, Chile. 161 p.

Homero. Iliada.

Homero, Odisea.

Heródoto. Historia. (1988). Introducción y notas de Carlos Schrader. Ed. Gredos. Madrid. España.

Jaeger, Werner. Paideia: los ideales de la cultura griega. (1992). Traducción de Joaquín Xirau y Wenceslao Roces. . Fondo de Cultura Económica. México D.F. 1151 p.

Lukasiewicz, Jan. La silogística de Aristóteles: desde el punto de vista de la lógica formal moderna. (1977). [tr. de la 2a. ed. por Josefina Fernández Robles]. Tecnos Madrid, España. 181 p. 
Manson Terrazas, Manuel. Filosofía del Derecho. (2006). Ed. Olejnick. Santiago de Chile.

Platón. La República. (1997). Introducción de Manuel Fernández-Galiano. Traductor José Manuel Pabón y Manuel Fernández-Galiano. Alianza Editorial Madrid.España. 1988, reimp. 1997.552 p.

Platón. Diálogos. (1987). Siete volúmenes. Ed. Gredos. Madrid. España.

Radbruch, Gustav. Introducción a la Filosofía del Derecho. (2005). Ed. Fondo de Cultura Económica. 9a reimpresión. México.

Solari, Enzo. Antígona o el poder de lo real. En: Persona y derecho: Revista de fundamentación de las Instituciones Jurídicas y de Derechos Humanos, ISSN 0211-4526, No. 39, 1998 (Ejemplar dedicado a: Estudio sobre "Antígona”), págs. 173-194. Disponible En: http://www.mercaba.org/ FICHAS/Teologia_latina/antigona_o_el_poder_de_lo_real.htm

Kunkel, Wolgang. Historia del Derecho Romano. (1989). Trad. J. Miquel, 9a ed. Barcelona, España.

Wolff, H.J. La Historia del Derecho Griego. Disponible en: http://www. restudioshistoricos.equipu.cl/index.php/rehj/article/viewFile/7/7

Yarza, InaKi. Historia de la filosofía antigua. (2005). Pamplona: Ediciones Universidad de Navarra. 314 p. 